\title{
A study of the cracks of prestressed concrete continuous box-girder bridge
}

\author{
Min Li \& Zhuang Wang
}

School of Environment and Civil Engineering, Jiangnan University, Wuxi 214122, China

KEYWORD: box-girder, concrete cracks; FEM, vertical temperature gradient, loss of vertical prestress

ABSTRACT: The finite element model of a prestressed concrete box-girder bridge was established , then the numerical simulation were carried out under the conditions of vertical temperature gradient. The effect of vertical temperature gradient is the important reason for the concrete cracks of box girder, and the loss of vertical prestressit has important influence to longitudinal stress of box girder.

\section{INTRODUCTION}

Prestressed concrete box girder bridges are widely used in both mid- and long-span bridge construction with the advantage of economy and aesthetics[1]. However, some effects that are especially critical in structures are poorly understood. Consequently, defects such as cracks still appear in concrete box girder bridges, And some quality problems appeared in actual operation of the process , the concrete cracks is the most common quality disease. With the existence of concrete cracks and further development, the cracks will seriously weakened bearer security and durability of bridge structure[2-4].

In this paper, based on the numerical analysis, four types of cracking of the bottom flange are presented, and the relationship among them is studied.

\section{NUMERICAL MODEL}

A continuous pre-stressed concrete rigid-frame highway bridge with span $53+93+53 \mathrm{~m}$, as shown in Fig. 1.The finite element analysis based on ANSYS[5] and finite element model of prestressed concrete continuous box girder bridge is established, as shown in Fig.2(a), and Fig.2(b) is model of prestressed steel.

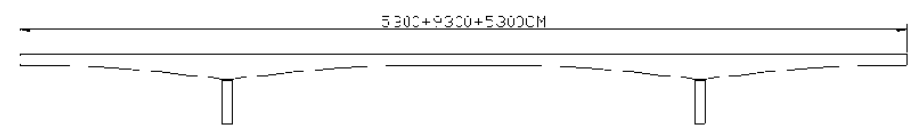

Fig. 1 Elevation of the bridge.

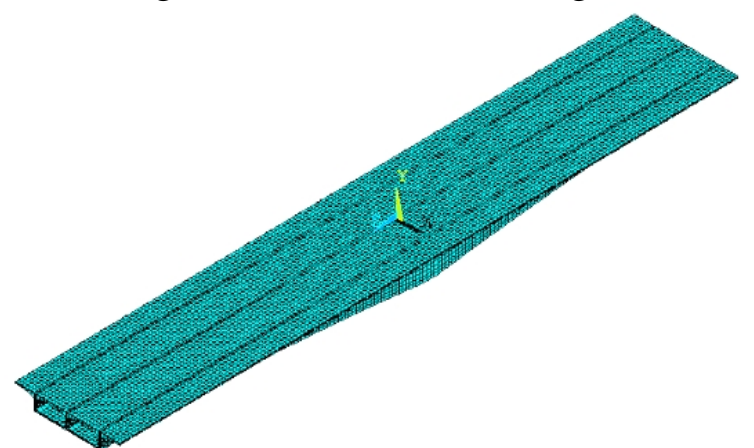

(a) FEM model of concrete box girder 


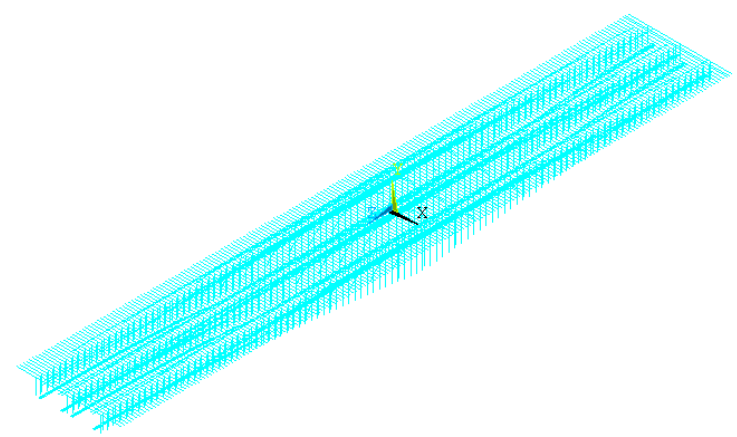

(b) FEM model of prestressed steel

Fig. 2 FEM model of PC box-girder bridge

A linear 3D model is developed for the stress field in the construc-tion stage. The SOLID45 element is used to model the concrete whereas the LINK8 element is used for prestressed tendons.A solid element, SOLID65, is used to model the concrete. The element has eight nodes with three degrees of freedom at each node. It is capable of simulating the plastic deformation and crack-ing in three orthogonal directions. The plain bars and tendons are represented by the 3D line elements. Two nodes are required for these elements. At each node, the degrees of freedom are identical to those for the SOLID65, which represents the concrete. The combination of these two elements can describe the box girder behavior. Ideally, in the present analysis, the reinforcement bars are assumed to be perfectly bonded to the surrounding concrete.

Then the different conditions of structure was carried out numerical simulation and analysis of the vertical prestress loss degree, transverse prestressing force and temperature field of prestress concrete continuous box beam in the roof and bottom plate and web is stress and principal stress influence characteristics and rules, so as to obtain the characteristics and rules of the cracks.

\section{ANALYSIS RESULTS}

Based on the aforementioned theory, the nonlinear analysis of the box girder is promoted. The program records a crack pattern at each applied load step. Fig. 11 shows the evolutions of cracks at the bot-tom flange of the box girder.

\section{Copying old text onto new file}

According to the Code for Design of Highway Reinforced Concrete and Prestressed Concrete Bridges and Culverts of China (JTG D62-2004), the vertical temperature gradient model set as: $\mathrm{T}_{1}=14^{\circ} \mathrm{C}, \mathrm{T}_{2}=5.5^{\circ} \mathrm{C}$, and concrete coefficient of expansion take $1.0 \mathrm{e}-5$, then analyze the longitudinal normal stress of the roof and base plate of box girder. And Fig. 3 is the stress nephogram roof and base plate of box girder with and without vertical temperature load.

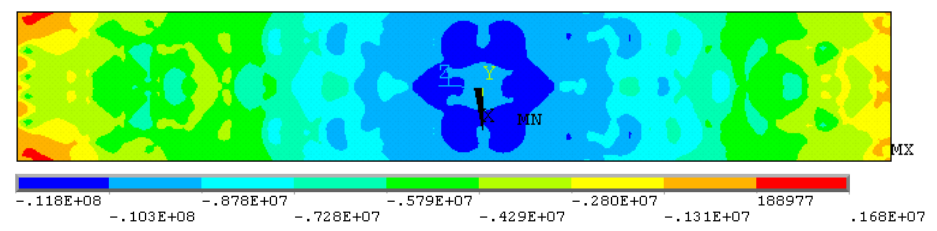

(a) without vertical temperature load ( Mpa )

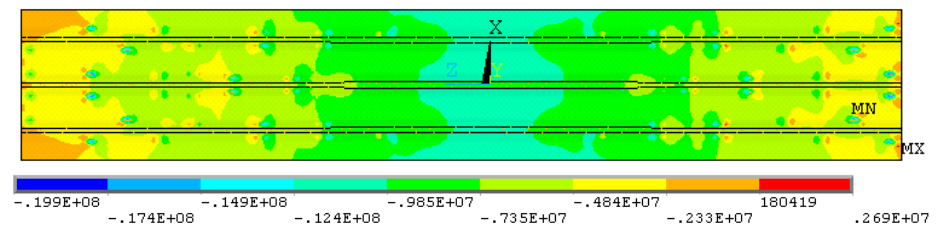

(b) with vertical temperature load ( Mpa )

Fig.3 Stress nephogram of roof plate without and with vertical temperature load 
As shown in Fig.3, with the vertical temperature load, the tensile stress of cross section of the roof gradually decreases to zero from end and half span to mid span, and negative stress increases gradually, the negative stress reach maximum nearby bearing of mid span.

In order to study the longitudinal normal stress with and without the vertical temperature gradient, then we analyze longitudinal normal stress of cross section in a half and a quarter span of roof /base floor of prestressed concrete continuous box girder, as shown in Fig. 4.

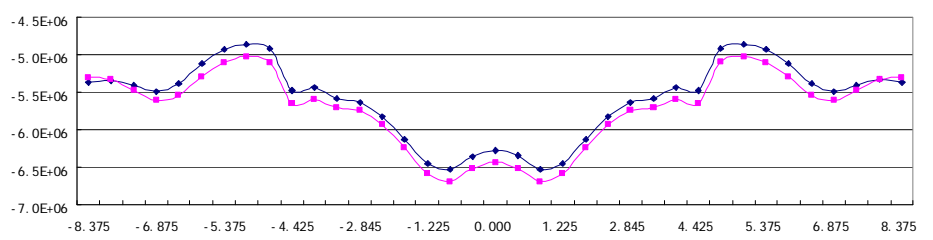

(a) longitudinal normal stress of cross-section in a half span of roof floor

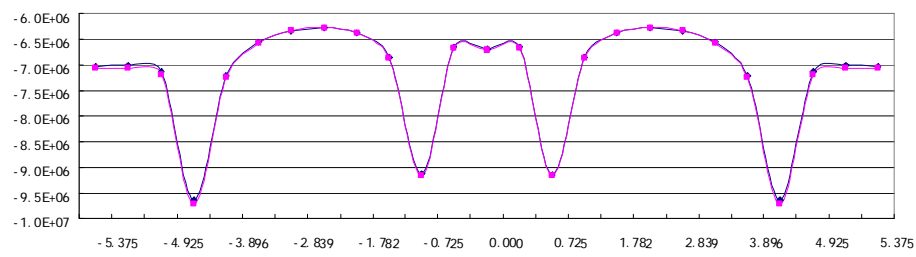

(b) longitudinal normal stress of cross-section in a half span of base floor

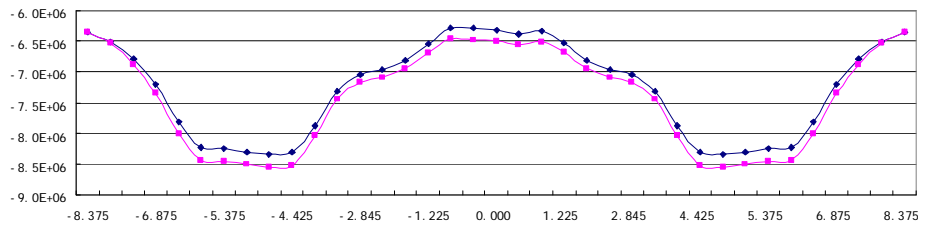

(c) longitudinal normal stress of cross-section in a quater span of roof floor

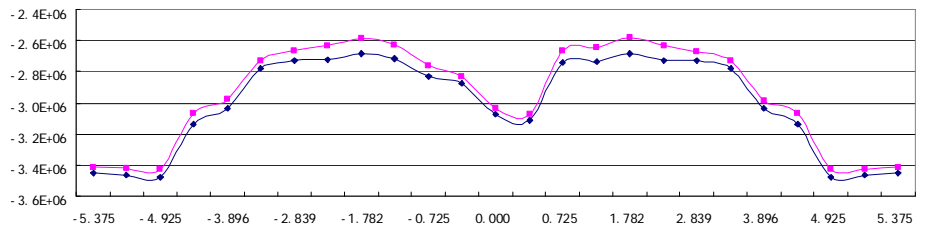

(d) longitudinal normal stress of cross-section in a quater span of base floor

Fig.4 longitudinal normal stress of cross-section in a half / quater span

$\rightarrow$ with temperature load $\rightarrow$ without temperature load

As shown in Fig.4(a), with vertical temperature gradient effect, the longitudinal normal stress of cross-section in a half span ranged $-6.70 \mathrm{Mpa} \sim-5.03 \mathrm{Mpa}$, and without temperature effect, the stress ranged $-6.54 \mathrm{Mpa} \sim-4.86 \mathrm{Mpa}$, the difference between the maximum negative stress is $0.18 \mathrm{Mpa}$.

As shown in Fig.4(b), with vertical temperature gradient, the longitudinal normal stress of the base plate changed is not obvious, with the vertical temperature gradient effect, the longitudinal normal stress of cross-section in a half span ranged $-9.72 \mathrm{Mpa} \sim-6.28 \mathrm{Mp}$, and without the vertical temperature gradient effect,the stress ranged $-9.65 \mathrm{Mpa} \sim-6.27 \mathrm{Mpa}$, the difference between the maximum negative stress is $0.07 \mathrm{Mpa}$.

With vertical temperature gradient effect, the longitudinal normal stress in a quarter span increases gradually from both sides of wing to the web, and decreased to the central web, As shown in Fig.3 (c), with the vertical temperature gradient effect, the longitudinal normal stress of cross-section in a quater span ranged $-8.55 \mathrm{Mpa} \sim-6.36 \mathrm{Mpa}$, and without the vertical temperature gradient effect,the stress ranged $-8.35 \mathrm{Mpa} \sim-6.29 \mathrm{Mpa}$, the difference between the maximum negative stress is $0.21 \mathrm{Mpa}$.

As shown in Fig.4(d), with vertical temperature gradient effect, the longitudinal normal stress of cross-section in a quater span of base floor decreased from both sides of the wing to the web, and 
increases to the central web, the maximum stress is near to the both sides wing, and the negative stress between the side webs and the central web changed is relatively flat. with the vertical temperature gradient effect, the longitudinal normal stress of cross-section in a quater span of base floor ranged $-3.43 \mathrm{Mpa} \sim-2.58 \mathrm{Mpa}$, and without the vertical temperature gradient effect, the stress ranged $-3.48 \mathrm{Mpa} \sim-2.68 \mathrm{Mpa}$, the difference between the maximum negative stress is $0.38 \mathrm{Mpa}$.

\section{The loss of vertical prestress}

The loss of vertical prestressit has important influence to longitudinal stress of box girder. Consider the different degrees loss of vertical prestress: (a) $0 \%$ of vertical prestress; (b) $50 \%$ of vertical prestress; (c) $100 \%$ of vertical prestress. And Fig. 5 is the roof longitudinal stress nephogram roof plate of box girder with different degrees loss of vertical prestress.

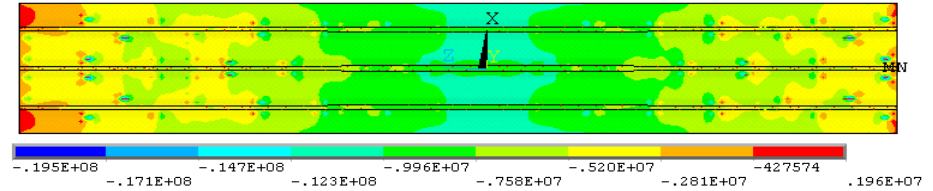

(a) $0 \%$ of vertical prestress (Mpa)

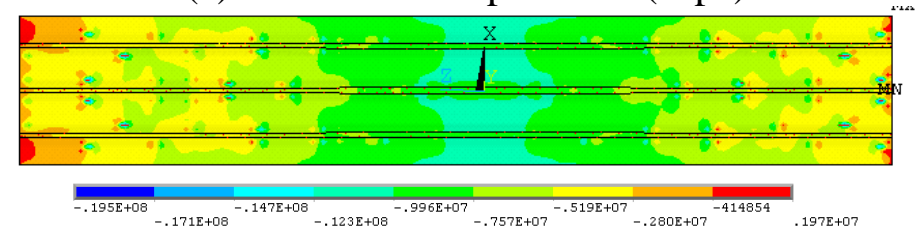

(b) $50 \%$ of vertical prestress (Mpa)

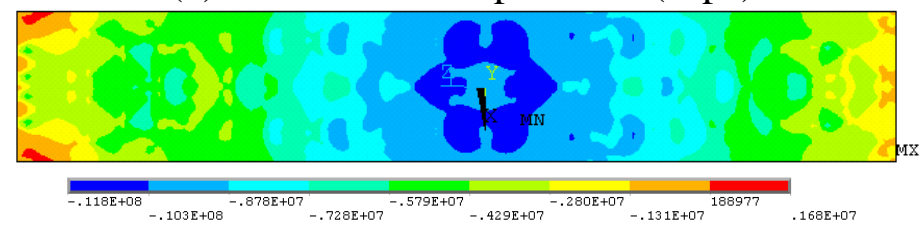

(c) $100 \%$ of vertical prestress (Mpa)

Fig.5 Stress nephogram of top plate with loss of vertical prestress

As shown in Fig.5, with the the different degrees loss of vertical prestress, the tensile stress of roof plate gradually decreases to zero from end and half span to the mid span, compressive stress increases gradually, and the compressive stress reach maximum nearby bearing of mid span.

As shown in Fig.5(a), with $0 \%$ of vertical prestress effect, the longitudinal normal stress of roof plate in a half span ranged from $-19.50 \mathrm{Mpa}$ to $1.96 \mathrm{Mpa}$, and the stress reach maximum nearby the end and the mid span, ranged from $-0.43 \mathrm{Mpa}$ to $1.96 \mathrm{Mpa}$, the maximum stress is about $1.96 \mathrm{Mpa}$, the tensile stress of roof plate gradually decreases to zero from side span and quarter span to the mid span, and mainly remains compressive stress, which ranged from - $0.43 \mathrm{Mpa}$ to $1.96 \mathrm{Mpa}$.

As shown in Fig.5(b), with 50\% of vertical prestress effect, the longitudinal normal stress of roof plate in a half span ranged from $-19.50 \mathrm{Mpa}$ to $1.97 \mathrm{Mpa}$, and the stress reach maximum nearby the side span and the mid span, ranged from $-0.41 \mathrm{Mpa}$ to $1.97 \mathrm{Mpa}$, the maximum stress is about $1.96 \mathrm{Mpa}$, the tensile stress of roof plate gradually decreases to zero from side span and quarter span to the mid span, and mainly remains compressive stress, which ranged from $-14.70 \mathrm{Mpa}$ to 2.80Mpa.

As shown in Fig.5(c), with $100 \%$ of vertical prestress effect, the longitudinal normal stress of roof plate in a half span ranged from $-11.80 \mathrm{Mpa}$ to $1.66 \mathrm{Mpa}$, and the stress reach maximum nearby the end and the mid span, ranged from $0.19 \mathrm{Mpa}$ to $1.68 \mathrm{Mpa}$, the maximum stress is about $1.96 \mathrm{Mpa}$, the tensile stress of roof plate gradually decreases to zero from side span and quarter span to the mid span, and mainly remains compressive stress, which ranged from-11.80Mpa to 4.29Mpa.

In order to study the longitudinal normal stress withr different degrees loss of vertical prestress, then we analyze longitudinal normal stress of cross section in mid span, a half side span and a quarter span of roof floor of prestressed concrete continuous box girder, as shown in Fig. 6. 


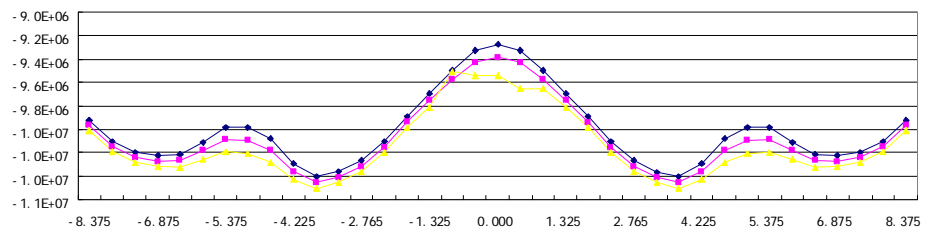

(a) longitudinal normal stress of cross-section in a mid span of roof floor

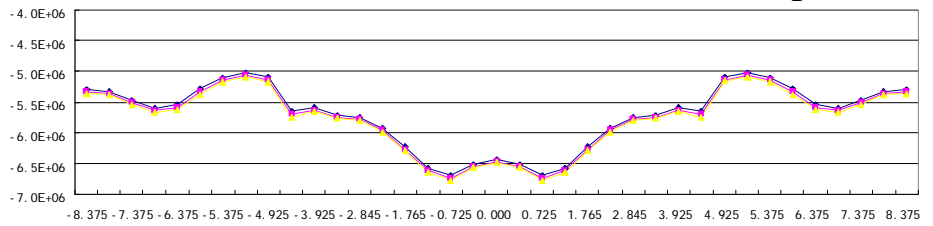

(b) longitudinal normal stress of cross-section in a side span of roof floor

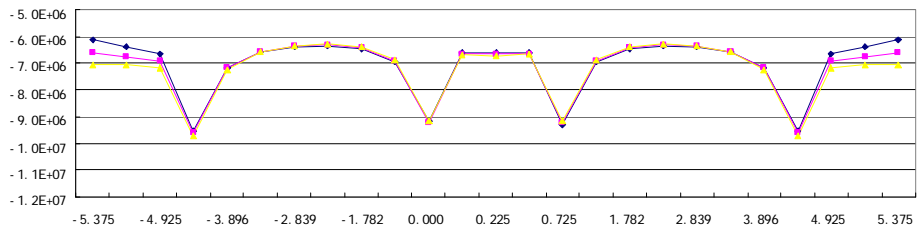

(c) longitudinal normal stress of cross-section in a side span of base floor

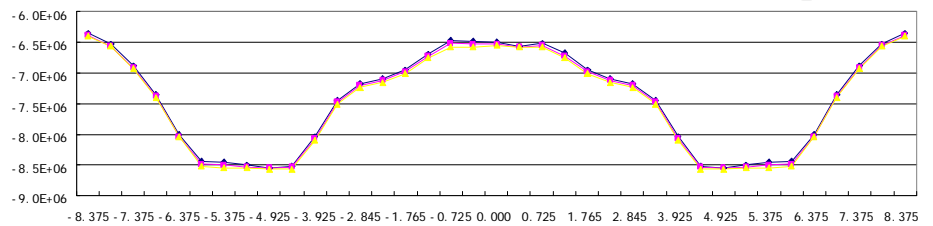

(d) longitudinal normal stress of cross-section in a quarter span of roof floor

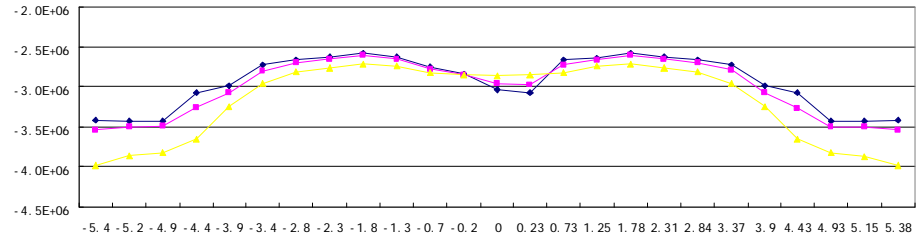

(e) longitudinal normal stress of cross-section in a quarter span of base floor

Fig.6 longitudinal normal stress of cross-section in a side / quater span of floor and base floor

In the Fig.6, with different degrees loss of vertical prestress, the change of longitudinal normal stress in middle span of floor is not obvious, the maximum stress is about $0.33 \mathrm{Mpa}$. And the change of longitudinal normal stress in half quater span of floor is also not obvious, the longitudinal normal stress of cross section in the half span of floor and the middle span base floor changes obvious, in the half span of floor, the maximum difference stress between the $0 \%, 100 \%$ loss of vertical prestress is $0.93 \mathrm{Mpa}$. in the middle span of base floor, the maximum difference stress between the $0 \% 、 100 \%$ loss of vertical pre-stress is $0.44 \mathrm{Mpa}$.

\section{CONCLUSION}

The effect of vertical temperature gradient is the important reason for the concrete cracks of box girder, and especially for the roof plate of prestressed concrete continuous box-girder bridge. The loss of vertical prestressit has important influence to longitudinal stress of box girder. especially for the longitudinal normal stress of cross section in the half span of floor and the middle span base floor, longitudinal normal stress of cross-section changes obviously.

\section{REFERENCE}

[1]Fan Lichu. Bridge Engineering. Beijing: China communications press, 2001.

[2]Angel C.Aparicio, Gonzalo Ramos Juan R.Cassas, Externally Prestressed high Strength ConcreteViaduct,Journal of Bridge Engineering.November, 2000 
[3]Mark G. stewart , Time-Dependent Reliability of Existing RC Structures , Journal of Strucutral Engineering.July, 1997

[4]Hans-Wolf Reinhardt,Martin Jooss.Permeability and self-healing of cracked concrete as a function of temperature and crack width.Cement and Conerete Research 33(2003)981-98

[5]ANSYS guide. ANSYS release 10.0. Houston: Swanson Analysis System; 2006. 